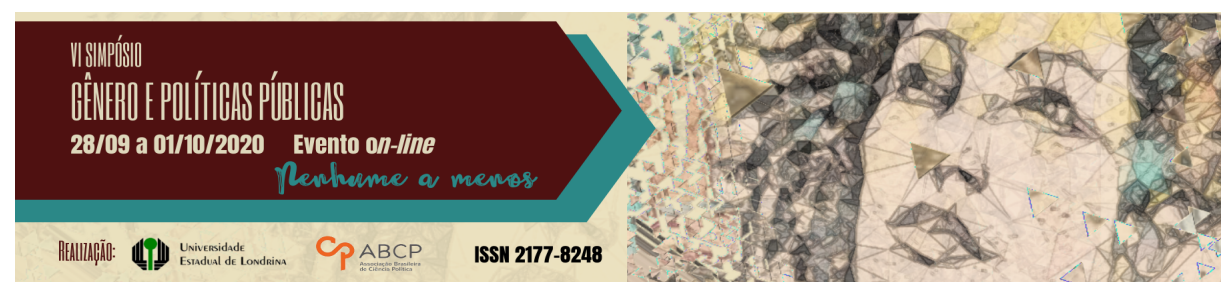

\title{
O papel da bissexualidade na construção da identidade masculina
}

\author{
Gustavo Favini Mariz Maia ${ }^{1}$
}

\begin{abstract}
Resumo
Pouco debatida até mesmo dentro das esferas de discussão LGBTQ, a bissexualidade sofre de preconceitos e apagamentos específicos. Em uma realidade marcada pela oposição dicotômica entre o homo e o hétero, a bissexualidade muitas vezes é representada como um campo nebuloso, permeado por dúvidas e falta de definições precisas que atingem até mesmo as vivências das pessoas monodissidentes. Em contraponto, a masculinidade hegemônica apresenta formas muito limitantes de constituição masculina. $\mathrm{O}$ presente trabalho busca, através de entrevistas com alguns homens que se identificam como bissexuais, situar as maneiras discursivas pelas quais são construídas narrativas sobre si tramando definições conceituais como masculinidade e virilidade.
\end{abstract}

Palavras-chaves: bissexualidade, masculinidade, construção de identidade.

\section{The role of bisexuality in the construction of male identity}

\section{Abstract}

Little debated even within the LGBTQ discussion spheres, bisexuality suffers from specific prejudices and deletions. In a reality marked by the dichotomous opposition between the homo and the hetero, bisexuality is often represented as a nebulous field, permeated by doubts and lack of precise definitions that affect even the experiences of monodissident people. In contrast, hegemonic masculinity presents very limiting forms of masculine constitution. This work seeks, through interviews with some men who identify themselves as bisexual,

\footnotetext{
${ }^{1}$ Mestrando em sociologia pela UFPR. gustavo.favini@gmail.com

GT 05 - Gênero, corpo e sexualidade
} 
to situate the discursive ways in which narratives are constructed about themselves, plotting conceptual definitions such as masculinity and virility.

Keywords: bisexuality, masculinity, identity construction.

\section{Foucault e a sexualidade no centro do debate das subjetividades}

Não é de hoje que a sexualidade desempenha um papel fundamental na constituição subjetiva das identidades. Michel Foucault, já no primeiro volume de "História da Sexualidade", assevera que a partir do século XVII o sexo passa a ser uma constante discursiva. Ora para restringi-lo, ora para fazê-lo extrapolar as ordens de repressão, os discursos sobre a sexualidade passaram a emergir em profusão.

A partir do século XVIII, ciências de controle populacional como a demografia passam a criar contornos mais sólidos e com isso, a proliferação de falas sobre o sexo é arranjada e pensada pelas novas áreas da ciência do controle dos corpos. O que antigamente era enxergado apenas como povo passa a ser visto também como população. O que implica trazer que a influência do Estado aos poucos se espraia para dentro dos lares através de efeitos como o controle de índices de natalidade, mortalidade, proliferação de doenças e concentração populacional.

Dentro deste contexto, sobre a sexualidade passam a incidir cada vez mais dispositivos de regulamentação com vistas a um controle e organização populacional através da otimização dos corpos. A homossexualidade passa a ser encarada como um mal maior. Se antes havia a figura do sodomita, um reincidente em práticas indesejadas, agora surgia a imagem do homossexual, não mais encarado enquanto figura, mas uma espécie na qual todos os seus atos eram influenciados por conta do seu sexo.

Em conjunto com desenvolvimento das ciências demográficas veio a reboque uma maior fixação da medicina em relação aos tipos sexuais considerados patológicos. Por debaixo da roupagem de objetividade purificada da ciência, havia um forte apelo moral, cujas 
classificações eram reforçadoras de estereótipos sociais. Através do discurso médico, práticas sexuais eram legitimadas e deslegitimadas, o que Foucault denomina de o surgimento de uma scientia sexualis. Em suas palavras

O importante é que o sexo não tenha sido somente objeto de sensação e de prazer, de lei ou de interdição, mas também de verdade e falsidade, que a verdade do sexo tenha se tornado coisa essencial, útil ou perigosa, preciosa ou temida; em suma, que o sexo tenha sido constituído em objeto de verdade (FOUCAULT, 2014, p. 63).

A organização desses fatores comunga com o que Foucault chama de dispositivo da sexualidade. Por ele são compreendidas as formas de se reprimir, gerenciar, definir e fazer falar os corpos e as subjetividades. Assim, o dispositivo da sexualidade não compreende meramente uma estratégia repressiva, mas de forma mais ampla que isso, impele todo sujeito a falar de si, a controlar a si mesmo dentro de regras preestabelecidas, que definem o que é normal e o que é patológico. Aos poucos, o dispositivo da sexualidade foi sendo articulado com outros dispositivos, como o dispositivo da aliança. Por ele era compreendido que uma sexualidade sadia seria aquela que encara o sexo como uma ferramenta de procriação, realizado apenas na privacidade do âmbito doméstico.

Salutar neste ponto mencionar que a aderência dos discursos médicos sobre a sexualidade não foi de início voltado ao controle da classe trabalhadora. Foucault adverte que a classe que se agarrou com maior vontade ao controle da sexualidade foi a burguesia, que se valia dos atributos de controle sexual como um símbolo distintivo, tal qual o sangue azul reclamado pela nobreza. Para além disso, fluía em profusão discursos sobre o potencial nefasto do sexo para as gerações futuras, como doenças que poderiam ser transmitidas de mãe para filho, condenando famílias inteiras. Deste modo, manter a linhagem familiar era um atributo que necessariamente era atravessado pelo sexo. 
O biopoder em desenvolvimento, segundo Foucault pode ser pensado através de duas formas de atuação complementares. Em primeiro lugar, através de uma anátomo-política do corpo humano, cuja finalidade principal estaria concentrada no adestramento dos corpos, no incremento de sua utilidade e docilidade. A segunda forma, denominada biopolítica da população, teria surgido a partir do século XVIII e teria como escopo estudar os índices de nascimentos, mortes e proliferações de doenças. A constituição e realização deste biopoder resultou em um atrelamento da lei, da normalização dos corpos e da sociedade.

Deste modo, a partir das transformações operadas a partir do século XVII, a sexualidade ganha papel preponderante na definição do sujeito para Foucault, que finaliza:

É pelo sexo efetivamente, ponto imaginário fixado pelo dispositivo da sexualidade, que todos devem passar para ter acesso à própria inteligibilidade (já que ele é, ao mesmo tempo, o elemento oculto e princípio produtor de sentido), à totalidade de seu corpo (pois ele é uma parte real e ameaçada desse corpo do qual constitui simbolicamente o todo), à sua identidade (já que ele alia a força de uma pulsão à singularidade de uma história) (FOUCAULT, 2014, p. 169).

\section{A bissexualidade invisível}

April S. Callis aproveita a imensurável contribuição de Foucault em "História da sexualidade" e acrescenta que a bissexualidade, enquanto orientação sexual não foi objeto do escrutínio médico-legal operado no século XIX. Em realidade, os estudos sobre bissexualidade realizados durante o período encaravam a bissexualidade a partir de duas frentes, que por vezes se confundiam: por um lado, era estudada enquanto condição anatômica, na qual havia a incidência de ambos os órgãos genitais em um mesmo corpo. Por outro, seria a potência latente que todo indivíduo carregava no início da vida, no período de formação 
infantil. Neste sentido, Freud advogava inicialmente que a bissexualidade poderia ser encarada como uma espécie de "hermafroditismo" que se espraiava para além da anatomia. Defendia ele que a bissexualidade poderia ser considerada também uma característica das primeiras etapas de desenvolvimento dos seres humanos, na qual a escolha do objeto sexual poderia voltar-se tanto para o mesmo gênero, quanto para o gênero oposto.

O que hoje entendemos como bissexualidade, à época era tão somente considerado como um subtópico das "inversões sexuais" 2. Em breves palavras, a teoria da inversão, defendida também por notórios médicos como Havelock Ellis e Richard von Krafft-Ebing arguia que a presença de atração e comportamento homossexuais eram oriundos da presença de um "espírito" inverso ao corpo, ou em outras palavras, uma construção psicossocial interna que fazia com que o indivíduo se enxergasse enquanto o oposto do seu sexo. Deste modo, homens invertidos se enxergariam, em realidade, como mulheres, o que, em uma latente defesa da heterossexualidade, justificaria a atração pelo gênero masculino.

Em decorrência da não existência de um tipo médico específico, a bissexualidade não era encarada enquanto uma espécie (tal qual os homossexuais, como nos traz Foucault). April Callis argumenta que pode derivar desta constatação a invisibilidade que a bissexualidade carrega até a contemporaneidade. Ela argumenta que a criação de um tipo médico patologizante da homossexualidade provocou apagamentos e perseguições severas. Entretanto, foi a partir da criação de uma "espécie" cuja conduta sexual era delituosa que se possibilitou posteriormente a criação de uma identidade engajada politicamente, como também a formulação e consolidação de uma espécie de discurso reverso que abriu campo para discutir social e politicamente os

\footnotetext{
2 Para Freud, em "Três ensaios sobre a sexualidade", a categoria que mais se aproxima da bissexualidade nos moldes em que é compreendida nos dias atuais seria a categoria de "invertido anfígeno", também denominados de "hermafroditas psicossociais", que seria uma subdivisão de comportamento entre os invertidos sexuais.
} 
conceitos projetados sobre a homossexualidade, construindo comunidades engajadas na luta antidiscriminatória.

Por carecer destas características, a comunidade bissexual não teve a mesma velocidade em se construir um movimento identitário tal qual construído por gays e lésbicas. Em razão da ausência de uma tipologia médica que definisse a bissexualidade enquanto orientação sexual, o próprio conceito de bissexualidade manteve-se aberto, provocando muitas vezes confusão entre os próprios bissexuais.

\section{Possibilidades do masculino}

A construção da masculinidade é um tópico que se alicerça desde a pequena infância. Daniel Welzer-Lang defende que a masculinidade é construída de forma mimética. Ao se inserir em ambientes cuja presença masculina seja exclusiva ou preponderante (conceito por ele denominado de casa-dos-homens), a jovem criança passa a aprender o que é e como é ser homem. Via de regra, o aprendizado se dá através da violência. Em primeiro lugar, uma violência contra si mesmo: dentro da casa-dos-homens, a masculinidade é ensinada dos mais velhos para os mais jovens. A inserção nesse círculo vicioso passa por primeiro domesticar seu corpo. Controlar seus gestos, seu tom de voz e treinar a habilidade nos esportes são as primeiras maneiras de imprimir a adequação àquele mundo.

Em um segundo momento, a violência que outrora era perpetrada contra si volta-se para os outros. A masculinidade enquanto lugar privilegiado depende da hierarquização de tudo aquilo que não se encaixa nos estreitos padrões da virilidade. Desta forma, aqueles que não apresentam padrões de dominação e aptidão nos esportes são relegados a uma segunda categoria. Diferenciar-se desta norma é equiparar-se ao oposto do masculino, qual seja, a feminilidade.

Raewyn Connell também traz em seus argumentos que a categoria hegemônica da masculinidade se contrapõe a tudo que é 
relacionado ao sexo oposto. Defende, portanto, a masculinidade enquanto categoria relacional. Ser homem implica ser tudo aquilo que uma mulher não é. Mister salientar que a masculinidade hegemônica é uma abstração calcada em uma base que pode ser definida como uma combinação entre a pluralidade de masculinidades e uma hierarquia estabelecida entre elas. São metas inalcançáveis, mas ainda assim perseguidas à exaustão. Salienta-se que a definição da masculinidade hegemônica não é estanque e impermeável. A categoria masculina de maior prestígio e reconhecimento possui valores maleáveis. Enquanto uma estrutura discursivo-histórica, a masculinidade pode enfrentar mudanças a depender da geografia e do período histórico considerado. Não obstante, Connell define que a masculinidade hegemônica pode ser encarada a partir de categorizações em três níveis distintos: global, regional e local. A categoria local seria formada pelas práticas e conceitos socioculturais que definem o que é ser homem dentro de uma circunscrição territorial como em um estado ou província. As influências de nível regional seriam aquelas presentes em uma abrangência territorial de um determinado país ou conjunto de países. E, por fim, de nomenclatura autoevidente, a masculinidade hegemônica conformada globalmente é aquela que apresenta características masculinas que são lidas de forma dominante e/ou prestigiosa ao redor de todo o globo.

Todo homem que não incorpore os valores hegemônicos de masculinidade são rebaixados a uma segunda categoria, conceituada como masculinidade subordinada. São hierarquizados dentro da lógica hegemônica, considerados como "homens falhos". Ainda que o lugar das mulheres seja o oposto em relação à masculinidade, não raras são as situações em que mulheres validam comportamentos considerados valorizados dentro da lógica hegemônica. O reforço à masculinidade hegemônica se exerce por grupos de mulheres na medida em que suas ações e imagem de si são voltadas de modo a se encaixar nesta estrutura hierárquica proposta. Connell trabalha esta categoria comportamental feminina como feminilidade enfatizada. Ela difere da masculinidade 
hegemônica pois ainda que defenda comportamentos majoritários ou com forte apelo no senso comum como sendo adequados às mulheres, não ganha o status de hegemonia, uma vez que em razão das relações de poder perpetradas pelo patriarcado, apenas os homens conseguem obter o privilégio de impor uma dominação tal que possa ser considerada hegemônica.

Ainda que seus estudos não se concentrem sobre masculinidades em específico, Judith Butler elabora um conceito de grande valia para o presente trabalho. Em "Problemas de gênero" a filósofa trabalha com o conceito de "gênero inteligível", que ela conceitua como "aqueles que, em certo sentido, instituem e mantêm relações de coerência e continuidade entre sexo, gênero, prática sexual e desejo." (BUTLER, 2019, p. 43) Os riscos de não alinhamento destas categorias implicam que o sujeito seja considerado detentor de um gênero "incoerente". Na prática, a matriz cultural que opera a inteligibilidade das identidades masculina e feminina também realiza o apagamento de todas as manifestações de identidade que a ela não se comungam.

Ocorre que a multiplicação e permanência das identidades indesejadas na matriz cultural é capaz de operar, de certa forma, uma subversão às regras de gênero. Essas identidades abjetas expõem os limites dessa matriz reguladora, ao passo que ao expô-la, permite que sejam elaboradas novas formas subversivas de desorganizar os critérios de gênero.

Deste modo, o trabalho realizado com homens bissexuais teve como força motriz buscar conceber as categorizações através das quais eventualmente homens bissexuais possam se sentir deslegitimados, uma vez que não coadunam os imperativos da matriz heterossexual, bem como captar quais as maiores dificuldades para a autoaceitação e o reconhecimento por terceiros. 
Com base nas breves considerações teóricas apresentadas previamente, estão sendo realizas entrevistas com homens declaradamente bissexuais de modo a verificar quais sentidos atribuem à sua sexualidade, bem como de qual maneira conseguem estruturar uma identidade pessoal a partir do modo como enxergam a relação entre masculinidade e bissexualidade.

Cabe salientar que as entrevistas aqui apresentadas constituem um pequeno fragmento de um trabalho de dissertação em andamento, cujo texto final tem como meta ser elaborado com base em entrevistas com dez homens bissexuais. Ainda que o trabalho de campo não tenha se realizado de forma integral, o bom andamento das pesquisas permite formular alguns pontos de particular interesse nas entrevistas realizadas. O presente artigo contará com o relato de apenas três dos sete entrevistados até então. O recorte ora realizado é motivado por algumas razões. Os três selecionados foram os primeiros com quem o trabalho fora inicialmente realizado. Suas falas foram eloquentes, de modo que acreditamos que o conteúdo fornecido seja suficiente para ser trabalhado relativamente a contento na presente proposta.

A realização das entrevistas se deu de forma semiestruturada. $\mathrm{O}$ roteiro de perguntas ${ }^{3}$ foi elaborado contendo dezenove questões, divididas em quatro eixos temáticos. As primeiras cinco perguntas direcionadas à apresentação do entrevistado e suas primeiras experiências sexuais. As questões seis a dez versam sobre a forma pela qual o entrevistado compreende a bissexualidade. Os temas das perguntas 11 a 13 relacionam-se com os signos e construções estabelecidas em relação ao gênero. Já o último eixo de questionamentos tem como mote as percepções sociais sobre a bissexualidade. No presente trabalho será abordado com maior ênfase os eixos três e quatro do formulário elaborado. No entanto, por tratar-se de entrevista semiestruturada, trechos de respostas cujas perguntas não estão compreendidas no roteiro poderão estar presentes.

3 Verificar apêndice. 
Em decorrência da pandemia de COVID-19, que se alastra em todo o país desde março de 2020, as entrevistas inicialmente previstas para ocorrerem presencialmente, tiveram de ser reformuladas de modo a possibilitar sua realização através de videoconferência.

Em relação aos entrevistados, a maior parte do contato com eles estabelecido advém da minha ligação com a ONG Dignidade, a qual recentemente passou a organizar grupos de discussão de pautas específicas da bissexualidade. No entanto, em decorrência do baixo número de homens bissexuais que acompanham as reuniões, outras formas de localizar homens bissexuais dispostos a relatarem suas experiências de vida também foram pensadas. A maneira pela qual foi possível encontrar mais pessoas abertas a falarem de si se deu através de aplicativos de encontro entre homens, especificamente Grindr e Scruff.

Previamente à entrevista, todo entrevistado era alertado sobre a total liberdade que disporia durante a gravação, podendo recusar-se a responder qualquer pergunta que considerasse constrangedora ou interromper a conversa a qualquer momento, ainda que episódios desta magnitude não manifestaram ocorrência. Também eram orientados de todas as informações que possibilitassem a identificação do entrevistado seriam suprimidas. Por fim, a cada entrevistado era solicitado o preenchimento de um formulário com informações como raça, escolaridade, faixa de renda e ocupação. Desta forma, os entrevistados que serão trazidos ao presente trabalho apresentam as seguintes características:

\begin{tabular}{ccccc}
\hline Nome & Idade & Raça & Renda & $\begin{array}{c}\text { Nível de } \\
\text { instrução }\end{array}$ \\
\hline Bruno & 23 anos & Branco & Até 1 S.M. & Graduando \\
\hline João & 28 anos & Branco & $\begin{array}{c}\text { Entre 5 a 8 } \\
\text { S.M. }\end{array}$ & $\begin{array}{c}\text { Especialização } \\
\text { lato sensu }\end{array}$ \\
& & &
\end{tabular}

4 Nomes fictícios. 


\begin{tabular}{|c|c|c|c|}
\hline Mohamed & 30 anos & Preto & $\begin{array}{c}\text { Entre } 5 \text { a } 8 \\
\text { S.M. }\end{array}$ \\
\hline
\end{tabular}

\section{Trabalho de campo}

\section{Mohamed}

Primeiro a ser entrevistado, conheci Mohamed através de aplicativo. Inicialmente suas experiências sexuais foram com mulheres. Sua primeira vez ocorreu por volta dos dezessete anos. No entanto, afirmava que a sua relação exclusivamente com mulheres não o satisfazia integralmente. Durante o período da faculdade teve sua primeira experiência com um homem. A aproximação aconteceu em uma festa da faculdade sem que, no entanto, tenham se relacionado sexualmente neste episódio. Em um intervalo de tempo próximo a um ano, chegou a "ficar" com mais dois homens. Após estas experiências, teve sua primeira relação sexual com outra pessoa do mesmo gênero, através de contato estabelecido através de aplicativo. Sua atração afetiva e sexual é voltada para pessoas cisgênero.

Perquirido sobre como elabora a bissexualidade, Mohamed argumenta que após alguma leitura sobre o tema, passou a ver que se identificava com a atração por mais de um gênero. Para ele, o desejo por homens e mulheres está entrelaçado. Afirma ter leve predisposição emocional para relacionar-se com mulheres. Sexualmente, no entanto, ocorre o inverso. Seu desejo manifesta frequência pouco maior em relação à homens.

Ao ser perguntado sobre o eventual conhecimento de outros homens bissexuais, Mohamed argumenta: 
Olha, eu já tive contato com outros caras, através de aplicativos, enfim, em que se diziam ser bi. Mas até que ponto, por exemplo, essa afirmação é verdadeira? Simplesmente, por exemplo, para mostrar que o ambiente em que o macho, né, essa palavra macho, essa palavra macho dominante, enfim, essa masculinidade aflorada ou que se força a ser aflorada não é um pressuposto para realmente, por exemplo, ser um argumento para dizer "olha, eu não gosto de afeminados" ou simplesmente para dizer que "olha, a parada comigo vai ser dessa forma", né? Então talvez alguns tenham, os caras com quem eu saí tenham, sim, se rotulados como bi, porém eu tenho ainda umas certas desconfianças, justamente por conta desse argumento que eu apresentei, né. Que hoje, por exemplo, se você fala, por exemplo, qualquer experiência que eu tenha tido em aplicativos, se você fala que é bi ou que, ainda, ou é macho, por exemplo, isso aflora uma certa masculinidade alfa, em que atrai outras pessoas pra relação ali que ele tá querendo, né, que a pessoa tá querendo. Mas ao mesmo tempo, não sei até que ponto, por exemplo, essa autodenominação bi que esses caras têm me dito realmente se vale para bissexual (Mohamed)

Uma fala que gerou certo grau de perplexidade, afinal era um homem bissexual deslegitimando a experiência de outros homens bissexuais. Na sequência, foi perguntado então de qual maneira um homem bissexual, na visão de Mohamed, deveria agir para ser legitimado como tal. Mohamed trouxe que não há maneiras de se afirmar que alguém é bissexual de fato tendo por base apenas as informações constantes em perfil de aplicativo. Sua resposta abriu margem para mais uma provocação. Se afinal de contas a definição de homens enquanto bissexuais em aplicativos não permite $o$ reconhecimento e a aceitação como verdade daquela orientação, será que a própria identidade de Mohamed também não seria contestada, se levada à cabo sua argumentação? Em tempo, Mohamed também relata em determinado momento da entrevista, que sua orientação sexual 
costuma ser questionada ou mal interpretada quando estabelece vínculo com mulheres. Para ele, a visão que as mulheres possuem sobre a bissexualidade masculina é desqualificadora através de dois vieses: o da promiscuidade e o da deslegitimação enquanto "homem de verdade".

Eu vejo que às vezes, embora, como eu falei, essa aceitação da masculinidade viril, ela tá mais, ela é mais hegemônica, eu vejo, por exemplo, que se eu trago no início de uma conversa essa afirmação, há um desinteresse logo de cara, enfim, ou até mesmo uma proposta pela qual eu não estou interessado, né? Quando eu digo que se eu digo no início, por exemplo, eu posso ouvir basicamente dois tipos de respostas: ou uma não aceitação ou então uma proposta pela qual não tô interessado, então [é como se a mulher dissesse] "Ah, tá. Então vamos fazer uma suruba." Então, nesse sentido, são raras essas propostas que surgem, mas já surgiram. Então eu vejo que não existe um padrão ali com as mulheres com as quais eu já me relacionei (Mohamed)

Se comparada a visão das mulheres que se relacionam com homens com a visão dos homens que se relacionam com homens, podemos notar a realização de uma hierarquização inversa, através da aproximação com uma noção de masculinidade hegemônica. Enquanto os homens que se relacionam com outros homens, na visão de Mohamed, valorizam o bissexual enquanto possuidor de uma "masculinidade alfa", as mulheres que se relacionam com homens por vezes apresentam desinteresse em relacionar-se com homens bissexuais, na experiência do entrevistado, por serem considerados promíscuos ou menos viris.

Em relação aos grupos de pessoas as quais Mohamed possui maior abertura para revelar sua orientação sexual, estão presentes suas irmãs, muito embora a revelação para seus pais não tenha ocorrido. $\mathrm{Na}$ visão de Mohamed, ainda que esta conversa não tenha acontecido formalmente com seus pais, ele alega que eles possuem alguma percepção de sua bissexualidade pela forma como se porta discursivamente, ao abordar temas e falar de assuntos que não são 
habituais para homens heterossexuais. Também possui abertura para falar de sua sexualidade com algumas amigas e afirma ter maior facilidade de abertura emocional e afetiva com mulheres.

Por outro lado, o entrevistado não se sente confortável para revelar sua orientação sexual a pessoas de seu grupo de trabalho, uma vez que não considera necessário se expor a tal ponto. Afirma que ser um homem bissexual apresenta desafios específicos, como ter de lidar com a ignorância e julgamento das pessoas. Apesar dos pontos negativos, Mohamed alega que a bissexualidade possibilita a vivência de experiências de vida únicas e plurais sexual e afetivamente, que não seriam possíveis caso se sentisse atraído por apenas um gênero.

\section{Bruno}

Bruno foi o segundo entrevistado, cujo contato inicial remonta ao convívio universitário na UFPR. Sua experiência revela aspectos diversos dos trabalhados por Mohamed. Vindo do interior para estudar em Curitiba, relata que desde a puberdade conseguia notar que não era heterossexual. Entretanto, em razão da criação tradicional que teve em sua infância, se viu compelido a adotar valores e manifestações comportamentais heteronormativas, o que gerava angústia e dificuldade em compreender-se. Seus dilemas de sexualidade eram internalizados, situação que era agravada por não compartilhar suas inseguranças com outras pessoas. Relacionou-se primeiro com mulheres. Seu primeiro namoro foi aos dezesseis anos. No entanto, mesmo durante o período de relacionamento era acometido pelas angústias em relação à sua orientação sexual.

Ignorada por muito tempo, a atração por homens veio à tona de maneira inescapável quando percebeu em si uma forte atração por um amigo gay. A atração era recíproca, o que gerou coragem em Bruno para relacionar-se brevemente com seu amigo após o término do seu namoro. Nas palavras de Bruno, a experiência foi um divisor de águas na compreensão de sua sexualidade. 
Aí depois que eu terminei eu fiquei com esse menino e foi um momento, assim, bem marcado na minha vida, que eu que aceitei a bissexualidade, né, esse meu lado homossexual, digamos. E de certa forma foi tarde, né. Porque eu sempre tentei fugir disso e me convencer de que era heterossexual, né. Mas depois dessa relação foi determinante para essa abertura, né, para a bissexualidade. (Bruno)

Outro fator que marca a relação de Bruno com sua sexualidade foi o fato de ter se revelado à sua família, em especial sua mãe. Ele alega que uma das motivações para contar sobre sua sexualidade para ela foi estar atualmente namorando um homem. Bruno relata que namorar um rapaz fez com que a questão da sexualidade tivesse "um ponto final", em suas palavras. Passou a encarar tanto sua família, quanto a sociedade de forma mais leve em relação a sua sexualidade. Bruno comenta que o episódio de revelação para sua mãe não foi dos mais agradáveis. Ao explicitar que não sentia atração apenas por mulheres, a mãe de Bruno ficou visivelmente frustrada, com reiteradas falas de que não esperava esse tipo de comportamento de seu filho.

Apesar da pouca receptividade inicial de sua mãe, Bruno relata que sabia que ela não o abandonaria. Comportamentos homofóbicos não eram do seu feitio. Apesar de ter se sentido mal em relação à forma como a mãe reagiu, Bruno demonstra que para ele foi um alívio poder dizer quem ele realmente é para as pessoas que ama. Afirma que com a revelação foi tirado um peso de suas costas. Declara, por fim, que hoje a relação de sua mãe com ele e seu namorado é tranquila, tendo sido recebidos na casa da mãe por algumas ocasiões sem que qualquer tipo de constrangimento ou ressentimento pudesse ser notado.

Apesar de atualmente Bruno considerar que sente atração por pessoas independente do gênero, a aceitação e a construção de sua identidade sexual foram permeadas por uma tentativa de normatização heterossexual, o que pode ter influenciado internamente sua forma de se portar. 
antes, assim, de eu compreender, assim, que eu sou bissexual e tal, eu tentava encontrar, assim, uma definição para mim, digamos, né. Porque por um tempo eu conseguia ter apenas atração afetiva por mulheres e atração sexual por homens, aí eu entrava em um conflito interno, de "bom, será que é isso mesmo? é isso ou aquilo?" e como eu tive uma criação muito heteronormativa eu acabei absorvendo muito disso, né. Aí também já entrei em questões de se antes eu tivesse me aceitado, será que eu teria, digamos, um estigma mais heteronormativo, mais masculino? Ou seria mais afeminado? Não sei. Mas eu acredito, assim, que pela minha criação, a heteronormatividade, assim, com comportamento mais masculino tem influência disso, né, da criação. (Bruno)

[...] com meu irmão, assim, ele geralmente quando procurava me ofender, a gente brigava ou coisa do tipo, ele tentava me atingir com comentários homofóbicos, né. Mesmo eu não tendo assumido nada ou coisa do tipo, ele geralmente usava insultos homofóbicos para me atacar. Aí também eu ia vendo o quanto isso era reprovável e tudo o mais, né. E até levava eu refletir sobre "será que eu tô dando muita pinta?" digamos, né. Porque não queria que ninguém percebesse, né, essa minha orientação, sei lá. Aí quando isso vinha à tona, seja por ofensa, seja por comportamentos homofóbicos eu sempre ficava receoso e refletindo, repensando, né, sobre meu comportamento. (Bruno)

No entanto, após a definição de sua identidade como bissexual, ele afirma que um dos pontos positivos de sua autoaceitação foi permitir-se ser quem realmente é, reduzindo o papel da importância da opinião alheia.

João

Das entrevistas realizadas, certamente João foi um dos entrevistados mais eloquentes e dispostos a falar sobre si. Através de 
contato mantido inicialmente pelo grupo de bissexuais da ONG Dignidade, João foi ouvido durante quase duas horas de conversa. Da mesma forma que Bruno, também veio do interior para estudar em Curitiba. Uma de suas maiores influências foi seu irmão mais velho, que era homossexual e morreu precocemente, vítima do HIV.

Relata que sua sexualidade esbarrou por diversas vezes na construção da sua masculinidade, bem como na relação com sua família. Muito embora atualmente ele tenha uma relação de abertura em relação à sua sexualidade com os parentes mais próximos, com uma de suas irmãs a situação se apresenta de modo um pouco mais nebuloso. Apesar de morarem juntos, ela revela pouca receptividade quando João tenta abordá-la para falar sobre sua bissexualidade. Ele acredita que o comportamento da irmã pode em parte ser explicado por conta das experiências traumáticas envolvendo a morte de seu irmão e em parte em decorrência dos ideais de masculinidade que são necessários quebrar em si e nos outros para ser aceito enquanto homem bissexual.

Em tempo, João também relatou dificuldades em se entender bissexual por conta da reação de pessoas próximas. Em determinado momento da entrevista, fala que uma ex-namorada, com quem manteve relacionamento por aproximadamente seis anos, apesar de saber desde o início de sua orientação sexual, não era capaz de compreende-la muito bem.

Ela sabia da minha bissexualidade. Porém ela tinha muito problema para lidar com isso. Então eu meio que, essas questões eu suprimia, sabe? Só que quando você suprime, tipo, né, reprime esse tipo de coisa, você também tá reprimindo uma parte sua, né. (João)

[...]Mas ela [a ex-namorada], assim, desde o começo ela já sabia, porém ela, assim, por umas questões de insegurança dela e tudo mais, ela tinha muito receio, assim, que de repente, eu sei lá, largasse dela e trocasse por um cara, mas aí é aquela coisa, né. Poderia ser por um cara ou por uma guria. Sabe, aquela coisa, aí entra justamente as construções de 
sexualidade, sabe? Que "ah, um dia ele vai enjoar de você, vai te trocar pelo..." sabe, assim? Então acho que tinha muito disso, até pela falta de informação dela, e daí só que eu também não tomei uma postura correta, que era justamente de elucidar ela nesse aspecto. (João)

Em outro ponto da entrevista, João também fala sobre como definições sobre a masculinidade interfere na subjetividade dos homens. Argumenta que livrar-se das características que se presumem presentes nos homens possibilita uma maior liberdade para se dedicar aos verdadeiros interesses. Também afirma que a construção de um papel hegemônico da masculinidade muitas vezes é nociva aos próprios homens, uma vez que através das expectativas deste papel, o homem não pode apresentar qualquer fraqueza ou fragilidade. Ao se impedirem de demonstrar seus sentimentos, muitos homens internalizam angústias que poderiam ser amenizadas se compartilhadas com outras pessoas, pontua.

Porque na minha perspectiva, né, cara, nunca, jamais eu tive um amigo que eu falasse de sentimento, que eu falasse de "sabe, cara, tô passando uma dificuldade e tal", um cara que tipo, sabe, pudesse contar num ponto assim de... era mais "ah, vamos encher a cara, bora aeee". Tipo, é isso, sabe? Mas nunca foi aquela coisa de tipo "putz, cara. Tô me sentindo mal, não tô bem. Tô me sentindo muito ansioso, não sei o quê". Hoje em dia que eu tenho amizades, assim, uns ou outros assim que, né, uma piazada, assim, que é muito mais cabeça aberta e tipo "cara, putz, tô me sentindo meio mal no trabalho, tô meio ansioso e tal" e o cara "é, cara. Eu também tô me sentindo meio assim e tal. Tá meio foda". Já tem uma abertura. Eu vejo que, aos poucos, assim, tem mudado isso. (João)

\section{Conclusão}

$\mathrm{Na}$ breve exposição apresentada, foi buscado trazer um fragmento das experiências de homens bissexuais e suas principais 
compreensões das dificuldades em conciliar sua orientação sexual com expectativas criadas em cima do comportamento masculino. Via de regra, a trajetória dos entrevistados foi marcada por alguns obstáculos internos e externos. Como obstáculos internos, podemos notar a grande carga de confusão mental e angústia que homens bissexuais carregam durante parte da vida, enquanto buscam consolidar sua orientação sexual. Parte dessa angústia pode ser atrelada aos obstáculos externos em se revelar homem bissexual. A pressão da sociedade, em especial de familiares próximos, atrelada à existência de um discurso que deslegitima a bissexualidade, ora definindo-a como uma fase, ora enquadrando-a como promiscuidade faz com que muitos homens sejam coibidos a revelar como realmente são.

Ademais, outros problemas relacionados à bissexualidade também atuam na forma como homens bissexuais são encarados. Via de regra, a invisibilidade que a bissexualidade enfrenta como um todo faz com que essas experiências de vida não ocupem grande espaço no imaginário coletivo. Considerand o o papel que a bissexualidade carrega na construção da subjetividade dos entrevistados, a invisibilização da sua sexualidade traz à ribalta uma invisibilização dos próprios sujeitos.

Não foi o intento defender neste breve trecho experiências generalizantes sobre a masculinidade bissexual. Pelo contrário: os relatos apresentam divergências em diversos aspectos, seja na forma de se relacionar com outras pessoas, na forma como criam uma percepção de si ou até mesmo na maneira como encaram reflexivamente o papel da masculinidade na construção da autoimagem. Portanto, a elaboração do presente trabalho mira na pluralidade e na riqueza de ser homem, com especial enfoque em homens bissexuais. Acreditamos que abrir o conceito que define o que é ser homem e subverter a importância que a masculinidade tóxica carrega em nossa sociedade seja um dos aspectos de maior emergência, para o bem dos próprios homens, para o bem de todes. 


\section{Referências}

BUTLER, Judith. Problemas de gênero: feminismo e subversão da identidade. Tradução de Renato Aguiar. 17. ed. Rio de Janeiro/RJ: Civilização Brasileira, 2019.

CALLIS, April S. Playing with Butler and Foucault: bisexuality and queer theory. Journal of Bisexuality, v. 9, p. 213-233, 2009.

CONNELL, Robert W.; MASSERSCHMIDT, James W. Masculinidade hegemônica: repensando o conceito. Revista Estudos Feministas, Florianópolis, v. 21, n. 1, p. 241-282, 2013.

FOUCAULT, Michel. História da Sexualidade: A vontade de saber. 1. ed. São Paulo/SP: Paz e Terra, v. 1, 2014.

FREUD, Sigmund. Três ensaios sobre a teoria da sexualidade (1905). In: Obras completas: três ensaios sobre a teoria da sexualidade, análise fragmetária de uma histeria ("O caso Dora") e outros textos (19011905). Tradução de Paulo César de Souza. 1. ed. São Paulo/SP: Companhia das Letras, v. 6, 2016. p. 13-172.

GARBER, Marjorie. Vice-Versa: Bissexualidade e o erotismo na vida cotidiana. Rio de Janeiro/RJ: Record, 1997.

WELZER-LANG, Daniel. A construção do masculino: dominação das mulheres e homofobia. Revista Estudos Feministas, Florianópolis/SC, v. 6, n. 2, p. 460-482, 2001. 


\section{Apêndice - Roteiro de Entrevistas}

1. Iniciar a entrevista perguntando as qualificações pessoais do entrevistado (nome, nível de instrução, raça, se se considera bissexual, idade);

2. Perguntar sobre as primeiras experiências de vida envolvendo a sexualidade. Quando passou a sentir atração sexual de forma ampla?

3. Quando teve o primeiro contato sexual?

4. Quando começou a sentir atração por mais de um gênero?

5. A atração envolve sentimentos apenas por homens e mulheres cisgênero ou também abarca identidades transgênero e não binárias?

6. Como definiria a bissexualidade?

7. Quando passou, de fato a se relacionar sexual e/ou afetivamente com outros gêneros (ou homens, caso a resposta à questão 5 restrinja a atração sexual apenas a homens e mulheres cis)?

8. Como e quando passou a aceitar e entender a própria bissexualidade?

9. Conhece outros homens que se identificam como bissexuais ou que manifestam desejo por mais de um gênero (ou eventualmente outras referências da cultura e mídia)?

10. Tem preferências para relacionamento sexual e/ou afetivo com algum gênero específico? (ex: tendência a namorar ou maior facilidade para conversar ou manter encontros casuais com algum gênero específico).

11. Consegue mencionar diferenças nas formas de se portar em relações com diferentes gêneros?

12. De que maneira acredita que ser homem interfere com sua orientação sexual?

13. Sua orientação sexual é uma parte importante da sua identidade? Por que? 
14. Como e para quem revelou sua bissexualidade pela primeira vez? Como foi?

15. A quais grupos sociais você revela sua orientação com mais facilidade (amigos, família, colegas de trabalho)?

16. Existe algum grupo que prefere não revelar sua orientação sexual? Por que?

17. Já sofreu preconceito por ser bissexual? Como lida/lidou com ele (caso a resposta a resposta seja afirmativa)?

18. É possível nomear dificuldades ou desafios específicos em ser um homem bissexual? Se sim, quais e por que?

19. É possível nomear pontos positivos específicos da bissexualidade masculina? Se sim, quais e por que? 